\title{
IMPLIKASIPRAKTIS-RELASIONAL DOKTRIN TRITUNGGAL: REFLEKSI INJILI
}

\author{
Manintiro Uling
}

\section{PENDAHULUAN}

Orang Kristen ada dan hadir di tengah-tengah dunia yang plural. Sebab, pluralitas itu niscaya dalam hidup manusia. Realitas kemajemukan tidak bisa dihindari dan ditolak, sehingga berbeda itulah hidup, menerima perbedaan itulah indahnya hidup. Hidup bersama, meskipun berbeda dalam banyak hal, saling menerima satu dengan yang lain, demikianlah semestinya hidup dijalani. Akan menjadi Ironis, jika gaya hidup yang eksklusif, tertutup, dan isolatif, bahkan separatis yang ditampilkan.

Namun faktanya, fenomena hidup yang eksklusif, tertutup dan cenderung hanya mau berbaur dengan yang sefaham, segolongan, dan sekeyakinan saja menjadi ciri khas sekelompok orang yang ekstrem atau singkatnya yang biasa disebut dengan gerakan radikalisme dan fundamentalisme. Menurut Karen Amstrong dalam bukunya "Berperang Demi Tuhan" mengatakan bahwa corak hidup yang eksklusif, separatis sudah ada sejak zaman Yesus, yang disebut dengan Farisisme. ${ }^{1}$ Begitupun di kalangan kekristenan sendiri. Di Filipina terdapat kelompok tertentu dari Gereja Katolik yang masuk ke dalam bidang politik dan hanya mengambil keuntungan bagi diri sendiri, tanpa memperhatikan sesama yang miskin. ${ }^{2}$ Yang kemudian hal ini mendapat kecaman keras dari Paus.

Kemudian dikalangan Protestan khususnya kelompok evangelikal sendiri dengan lahirnya gerakan fundamentalisme yang awal mulanya berorintasi pada pembelaan dan proklamasi kembali iman, yang kemudian berubah sikap menjadi lebih sensitif, cepat tersinggung, memiliki pemikiran yang tertutup, intoleransi, merasa superior. ${ }^{3}$

1 Karen Amstrong,Berperang Demi Tuhan(Jakarta: Mizan,2013), 288.

2 Egidius Patnistik, "Mengapa Tuhan Membiarkan Anak-anak Jadi Pelacur?" International Kompas.Com; ( Januari 2015 ) http://internasional.kompas.com/ read/2015/01/18/14391891/ Mengapa.Tuhan. Membiarkan. Anakanak. Jadi.Pelacur; diakses 16 Ferbuari 2018.

3 Nancy T. Ammerman, "The Dynamics of Christian Fundamentalism: An Introduction,"dalamAccounting for Fundamentalism, Marty\& Appleby, eds (Chichago: University of Chichago Press, 2003), 13-17. Lih.juga Robert Wuthnow and Mattew P. Lawson, "Sources of Christian Fundamentalism in the United States, (Chichago: University of Chichago Press, 2003), 18-56. 
Tak bisa dipungkiri mentalitas ghetto begitu mewarnai gereja sehingga gereja menjadi terasing dalam masyarakat, itulah sebabnyaseruan integrasi bukan ghetto menjadi signifikan, ${ }^{4}$ oleh PGI dalam Sidang Raya XI tahun 1989 menegaskan kembali komitmen mereka agar terlibat aktif dalam pembangunan skala nasional dan bangsa. Yang pada prinsipnya menjauhkan sikap eksklusif dan sikap apatis sebagai gaya hidup gereja. ${ }^{5}$ Hal yang senada dalam kritikan Eka Darmaputera yang juga sangat tajam terhadap teologi yang dianut oleh kelompok tertentu yang tak kurang introvert, eksklusif, individualistis dan dualistisnya, ${ }^{6}$ yang tentu saja berpengaruh langsung pada gaya hidup praksis dari para penganutnya.

Karena itu, berdasarkan latar belakang masalah di atas, maka penulis mencoba merumuskan aspek praktis-relasional doktrin Tritunggal, sebagai pijakan etis-praktis orang Kristen berelasi dengan sesamanya. Seperti apa yang dikatakan oleh Leith bahwa: the Triune God is both "unity" and "diversity" ("one God in Three Person"), with the communion of love binding together, so the cosmos itself reflect this same unity and diversity as the expression of the creative of the Triune of God. ${ }^{7}$

Disatu sisi, biasanya tulisan tentang Tritunggaldi kalangan kaum Injili lebih banyak dalam kajian yang bersifat apologetik, karena memang doktrin ini seringkali disalah-mengerti atau dipahami oleh golongan tertentu. ${ }^{8}$ Tulisan ini mencoba melihat dari sisi yang berbeda denganmereformulasi doktrin Tritunggal yang ditinjau dari aspek Praktis-relasional dalam perspektif Injili.

4 Huub J. W. M. Boelaars, Indonesianisasi (Yogyakarta: Kanisius, 2005), 448.

5 Sidang MPL=PGI 1992 di Tentena, Poso: Sebuah Tonggak Historis" dalam Weinata Sairin, Gereja, Agama-Agama Dan Pembangunan Nasional: Bunga Rampai (Jakrta: Gunung Mulia 2006), 145.

6، Menuju Teologi Kontekstual” dalam Eka Darmaputera., Ed, Konteks Berteologi Di Indonesia: Buku Penghormatan Untuk HUT ke-70 Prof. Dr. P. D. Latuihamallo (Jakarta: BPK Gunung Mulia, 2004), 8.

John H.. Leith, Introduction to the Reformed Tradition (Atlanta: John Knox Press, 1977), 96.

8 Lihat misalnya dalam tulisan Togardo Siburian, yang sarat dengan perspektif apologetik. "Gagasan Trinitas Keselamatan Di Tengah-Tengah Monoteisme Ekstrim: Suatu Afirmasi Apologetis” dalam Jurnal Stulos. Vol. 14 No 2 (Desember 2015),125-157. 


\section{RUMUSAN DOKTRIN TRITUNGGAL}

Doktrin Tritunggal merupakan doktrin yang rumit, ${ }^{9}$ namun bukan berarti doktrin ini salah atau keliru. Sebab konfesi akan Tritunggal adalah kebenaran dan juga misteri ilahi ${ }^{10}$ yang hanya dapat diterima oleh dan melalui iman. Bukan juga terjebak pada sikap yang fideistik, karena bagaimanpun juga dalam argumentasinya memiliki penalaran yang rasional, meskipun juga harus diakui untuk memahaminya sistem pikir "akal yang diperluas" atau melampaui akal harus dipertimbangkan, yang kemudian sumber utama adalah pada apa yang dikatakan oleh Alkitab.

Allah Tritunggal menurut Grudem dapat didefinisikan sebagai: "God eternaly exists as Three persons, Father, Son, and Holy Spirit, and each person is fully God, and There is one God. ${ }^{11}$ Memang istilah Tritunggal tidak pernah muncul di dalam Alkitab, tetapi tidak berarti tidak diajarkan dalam Alkitab. Justru Alkitab memberikan data yang cukup lengkap baik secara eksplisit maupun implisit tentang konsep Tritunggal. ${ }^{12}$ Karena itu, sangat tepat apa yang dikatakan oleh Louis Berkhof bahwa: "doktrin Allah Tritunggal

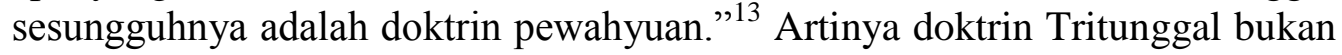
hasil rumusan gereja, tetapi penyataan Allah sendiri dalam Alkitab. Allah yang tersembunyi (Deus Absconditus), telah menyatakan diri-Nya sendiri (Deus Revelatus). Ini merupakan perspektif Injili.

Oleh karena itu dalam pembahasan tentang rumusan doktrin Tritunggal akan diuraikan dari beberapa aspek, yaitu: Presuposisi, Pernyataan Doktrinal.

\section{$\underline{\text { Presuposisi }}$}

Dalam usaha membangun sebuah teologi, peran presuposisi menjadi sangat penting karena akan sangat menentukan arah dari bangunan teologi itu. Presuposisi bisa dikatakan sebagai asumsi dasar, pra-anggapan, prapengetahuan seseorang dalam usahanya menafsir atau melihat sesuatu. Dengan

9 Ada yang mengatakan bahwa doktrin Allah Tritunggal sulit dimengerti dan jika dimengerti, kita tidak mungkin mengerti secara tuntas. Ini alasan sehingga ilustrasi atau analaogi apapun tidak bisa menjelaskannya Tritunggal. Muriwali Yanto Matalu, Dogmatika Kristen Dari Perspektif Reformed (Malang: GKKR, 2017), 237. Memang sulit untuk mengerti sepenuhnya Pribadi Allah, pengertian itupun dibangun atas dasar iman dan dari sumber utama revelasi, Alkitab itu sendiri.

10 Bisa lihat juga Dupage Declaration, 1990 dalam J. I. Packer \& Thomas C. Oden, Satu Iman: Konsensus Injili (Jakarta: BPK Gunung Mulia, 2011), 59.

11 Wayne Grudem, Systematic Theology: An Introduction to Biblical Doctrine (Grand Rapids: Inter-Varsity Press, 1994), 226.

12 Penjelasan yang sangat komprehensif bisa dilihat dalam buku Herman Bavink, Dogmatika Reformed 2: Allah dan Penciptaan (Surabaya: Momentum, 2012), 326-348.

13 Luis Berkhof, Teologi Sistematika 1: Doktrin Allah (Surabaya: Momentum, 2011), 147. 
kata lain, pentingnya metode teologi sistematik, dimana didalamnya terdapat presuposisi Teisme Kristen, Allah sebagai the Absolut, self-conscious Being (Keberadaan Mutlak yang berkesadaran diri) menjadi Principium Essendi (Prinsip Utama). ${ }^{14}$ Keberadaan yang Mutlak yang berpribadi tersebut adalah Allah Tritunggal berdasarkan special revelation. Van Til menyebut ini sebagai presuposisi Ultimat. ${ }^{15}$ Dengan kata lain, presuposisi Kristen bersifat supranaturalistik-revelasional.

Oleh karena itu, presuposisi Teisme Kristen bersifat Trinitarian, kepercayaan kepada Allah Tritunggal. $^{16}$ Dimana doktrin Tritunggal mencerminkan keyakinan kepada Allah Bapa, Allah Putra dan Allah Roh Kudus. Serta keyakinan akan inkarnasi Yesus Kristus dalam kerangka penebusan atau karya keselamatan umat pilihan-Nya. Ini merupakan worldview Kristen dan melalui formulasi doktrinal akan menjadi lifeview ataupun habit dalam hidup orang Kristen, dalam berelasi dengan sesamanya.

\section{Tritunggal Sebagai Basic Beliefs}

Doktrin Tritunggal merupakan teisme Kristen, sekaligus basic beliefs ${ }^{17}$ yang mencirikan kekhususan iman kekristenan berdasarkan revelasi. Seperti yang dikatakan oleh Karkkainen bahwa:

Doktrin Tritunggal bukan hanya prinsip penstrukturan dari doktrin Kristen, melainkan juga cara mengidentifikasikan Allah Alkitab. Doktrin Tritunggal ialah apa yang secara mendasar mencirikan doktrin Kristen tentang Allah dan dengan demikian telah membedakan konsep penyataan Kristen sebagai Kristen, berbeda dengan semua doktrin Allah yang lain. Doktrin Tritunggal ialah satu-satunya jawaban Kristen yang mungkin atas pertanyaan siapa Allah yang menyatakan diri-Nya. ${ }^{18}$

Karena itu, doktrin Tritunggal mencerminkan keyakinan orang Kristen yang kokoh mengenai Allah Bapa, Putra dan Roh Kudus berdasarkan Alkitab sebagai wahyu khusus yang adalah sumber prinsip dan pengetahuan bagi kehidupan etis praktis orang Kristen.

14 Lih, Cornelius Van. Til, Pengantar Theologi Sistematik: Prolegomena Dan Doktrin Wahyu, Alkitab Dan Allah, Terj. (Surabaya: Momentum, 2010), 30-33.

15 John M. Frame, Suatu Analisa Terhadap Pemikirannya Cornelius Van Til (Surabaya: Momentum, 2002), 143.

16 Ronald H. Nash, Konflik Wawasan Dunia(Surabaya: Momentum, 2008), 47.

17 K. Scott Oliphint, Reason For Faith: Philosophy In The Service Of Theology (Phillipsburg: P\&R Publishing, 2006), 35.

18 Veli-Matti Karkkainen, Tritunggal \& Pluralisme Agama (Jakarta: BPK Gunung Mulia, 2013), 21-22. 


\section{Doktrin Tritunggal Sebagai Akar Dari Semua Doktrin Kristen}

Doktrin Tritunggal adalah pusat dari iman Kristen, tanpa doktrin Tritunggal kekristenan kehilangan konten dan esensi dari iman Kristen itu sendiri. Doktrin Tritunggal sebagaimana Allah sendiri telah mewahyukannya (Deus Revelatus). Dengan demikian doktrin ini merupakan inti dari iman Kristen, akar dari semua doktrin dan seluruh ativitas bergereja, bahkan semua doktrin yang lain tersusun dan berpijak pada doktrin Tritunggal itu sendiri. Sebab itu, seperti yang dikatakan oleh Timo bahwa:

Tanpa iman kepada Allah Tritunggal, pemahaman Kristen tentang semua hal dalam iman Kristen tidak memiliki keunikan apa-apa. Tanpa iman kepada Allah Tritunggal, ibadah dan penyembahan Kristen hampa, tak bermakna dan kehilangan pengharapan. Iman Kristen berbeda dari agama-agama yang kita kenal. ${ }^{19}$

Sebab itu, doktrin Tritunggal adalah doktrin yang sangat penting dalam teologia Kristen.Seperti yang dikatakan oleh Grudem bahwa: "the doctrine of the Trinity is one of the most important doctrines of the Cristian faith". ${ }^{20}$ Senada dengan apa yang dikatakan oleh Erickson bahwa: "the doctrine of the Trinity is crucial for Christianity. "21 Jatuh bangunnya iman Kristen sungguhsungguh bergantung pada benar-tidaknya doktrin ini. Sebab, hampir semua pokok penting dalam iman Kristen, bergantung pada ajaran bahwa Allah adalah tiga dalam satu. ${ }^{22}$

Jadi, doktrin Tritunggal adalah fondasi keseluruhan Teologi Kristen. Itu juga berarti bahwa doktrin Tritunggal menjadi fondasi bagi ortopraksi orang Kristen, khususnya aspek relasi baik di gereja ataupun relasinya dengan dunia.

\section{Pernyataan Doktrinal}

Untuk dapat memahami korelasi antara doktrin Tritunggal dari aspek praktis-relasional, maka diperlukan pernyataan doktrin Tritunggal, yang secara niscaya menjadi norma absolut bagi orang Kristen dalam berpikir, bersikap dan bertidak terhadap sesama yang yang plural di dunia ini. Kerangka berpikir sistematik mengenai konsep Allah Tritunggal sebagaimana saya gambarakan di bawah ini:

19 Ebenhaizer I. Nuban Timo, Aku Memahami Yang Aku Imani (Jakarta: BPK Gunung Mulia, 2012), 1.

20 Wayne Grudem, Systematic Theology an Introduction to Biblical Doctrine (Leicester: Inter-Varsity Press, 2005), 226.

21 Milard J. Erickson, Christian Theology Second Edition (Grand Rapids: Baker Books, 2003), 347.

22 Bruce Milne, Know Truth: Handbook of Christian Belief (Downers Grove: InterVarsity Press, 1982), 90. 


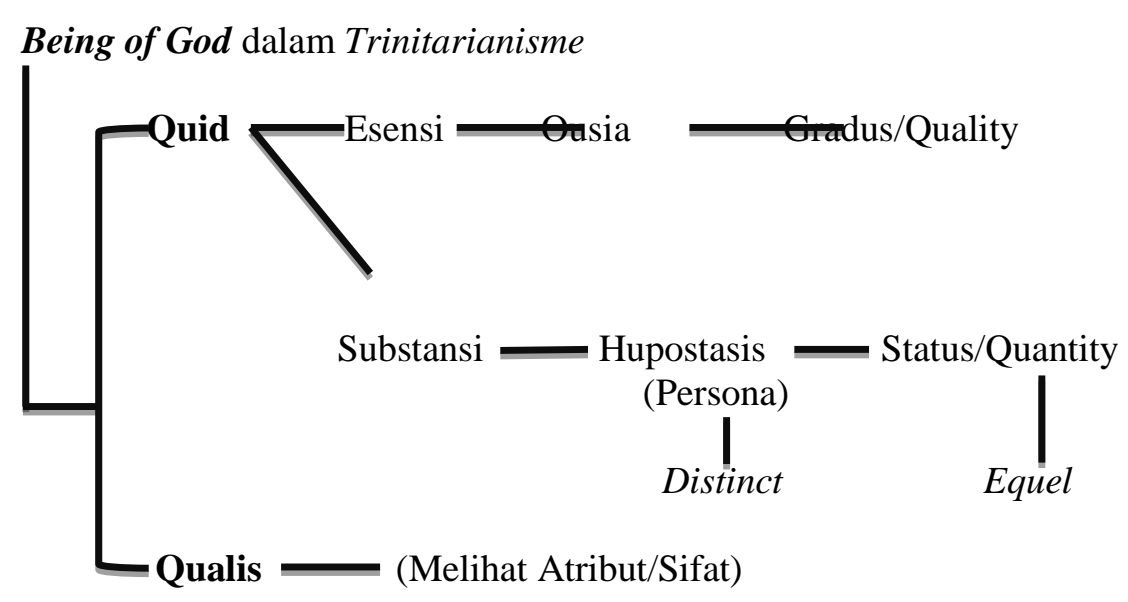

Dari quid melihat keberadaan Allah dalam dua persepsi, yaitu esensi dan substansi. Esensi untuk melihat "apakah" Allah pada hakekatnya (ousia), qradus atau kualitas materi sebab Ia adalah Theos (kata benda tapi, bukan materialisme) Allah berbeda (different) secara kualitas sebab Ia "beyond the matter" dan berada diluar ruang dan waktu, hanya saja ini upaya manusia mencoba melihat Allah dari dalam ruang dan waktu, sementara substansi melihat "siapakah" Allah dari sisi persona (person) untuk melihat status atau kuantitas, dari sinilah melihat Allah Tritunggal dari segi kuantitas, dimana secara personal beda (distinct) akan tetapi, secara status adalah sama (equal), juga dalam aspek qualisnya dalam sifat-sifat dan atribut-Nya. ${ }^{23}$

Oleh sebab itu, Pernyataan doktrin Tritunggal secara ringkas, diungkapkan dalam pengakuan Iman Westminster yang berkata bahwa:

"Di dalam Allah yang esa, terdapat tiga Pribadi, yang adalah satu dalam substansi, kuasa dan kekekalan; Allah Bapa, Allah Anak dan Allah Roh Kudus. Bapa bukan dari apapun, juga bukan diperanakkan oleh siapapun, juga bukan keluar dari apapun; Anak diperanakkan dari Bapa sejak kekekalan; Roh Kudus keluar dari Bapa dan Anak sejak kekekalan." 24

Lebih lanjut, Erickson memaparkan Istilah Tritunggal, harus di pahami dalam 3 pendekatan yang berdasar pada Alkitab, yaitu, "The Oneness of God,

23 Bdk. Luis Berkhof, Teologi Sistematika.., 58. Berkhof sendiri lebih memilih penjelasan dari perspektif qualis daripada quid. Dengan argumentasi bahwa data dalam Alkitab sangat cukup dan lebih mudah berbicara mengenai atribut-atribut atau pun sifat-sifat Allah, daripada berbicara dari segi quid yang menurutnya sangat spekulatif.

24 Pengakuan Iman Westminster 2.3, dikutip oleh Cornelius Van Til, Pengantar Theologi Sistematik: Prolegomena Dan Doktrin Wahyu, Alkitab Dan Allah (Surabaya: Momentum, 2010), 402. 
The Deity of Three, dan Three-in-Oneness. ${ }^{25}$ Jika diparalelkan antara Kredo Westminster di atas, dan pendekatan yang dipakai oleh Erickson, maka penulis menguraikan secara terperinci melalui proposisi-proposisi sebagai berikut:

\section{Singularitas Allah}

Singularitas Allah artinya yang menekankan kesatuan Allah, faktanya bahwa Ia secara angka satu dan bahwa Ia unik. Cakupan arti logis dari istilah ini adalah hanya ada satu keberadaan Ilahi, tidak mungkin ada lain, selain satu keberadaan Ilahi dan semua keberadaan lain ada dan melalui serta kepadaNya. ${ }^{26}$ Dalam keberadaan Ilahi hanya ada satu esensi yang tidak terbagi (ousia esentia). Allah adalah satu dalam esensi-Nya atau dalam natur konstitusional-Nya.

Alkitab mencatat dalam Kitab Ulangan 6:4 menggunakan kata אָָ 'echad, yang berarti satu. Kata echad dipakai dalam berbagai variasi misalnya diartikan sebagai a compound one (satu gabungan), semua satu, satu dengan. Kata Ibrani lain yang dekat berkaitan dengan echad dan digunakan bergantian dengan kata badhadh berarti sendiri, yang pertama.

Kata echad bukan an absolute one (satu yang mutlak). ${ }^{27}$ Kata itu digunakan misalnya untuk satu tandan anggur atau mengatakan bangsa Israel merespons sebagai satu bangsa. ${ }^{28}$ Sebaliknya kata Ibrani yang berarti satu yang mutlak (an absolute one), mengunakan kata bukan kata yachiyd dipakai dalam konteks Allah yang esa, tapi kata echad. Selanjutnya, Boice juga mengatakan bahwa echad bukan satu dalam isolasi, satu dalam kesatuan. Faktanya kata itu tidak pernah digunakan dalam bahasa Ibrani sebagai suatu entitas tunggal. ${ }^{30}$ Ini bukan hanya berarti satu-satunya Allah yang benar di dunia ini, tetapi juga artinya tidak ada Allah lain.

\section{"Pluralitas" Allah}

Ini tidak berarti ada banyak Allah (politeisme), tetapi adanya "kejamakan" dalam diri Allah. Secara evidensial, ditunjukkan oleh Alkitab, misalnya melalui penggunaan nama Allah dalam Perjanjian Lama, dipakai kata אֶלה (elohim) dalam Kejadian 1:1 yang merupakan kata bentuk jamak

25 Millard J. Erickson, Christian Theology (Grand Rapids: Baker Book House, 1986), 323.

26 Luis Berkhof, Teologi Sistematika 1 Doktrin Allah (Surabaya: Momentum, 2011), 99.

27 G. Johanes Botterweck dan Helmer Ringgren. ed, Theological Dictionary of The Old Testament Vol. I (Grand Rapids: William B Eerdmans Publishing Company, 1974), 193194

28 James Montgomery Boice, Dasar-Dasar Iman Kristen (Surabaya: Momentum, 2011), 113.

29 G. Johanes Botterweck dan Helmer Ringgren. ed, Theological Dictionary of The Old Testament Vol. I., 194.

30 James Montgomery Boice, Dasar-Dasar Iman Kristen., 113. 
(plural). Demikian juga, banyak referensi ayat Alkitab yang mengindikasikan adanya "kejamakan" dalam diri Allah, seperti Kejadian 1:26: Berfirmanlah Allah: "Baiklah Kita..."; Kejadian 3:22 "... Sesungguhnya manusia itu telah menjadi seperti salah satu dari Kita, Begitu pun dalam Kejadian 11:7, "Baiklah Kita turun..." dan masih banyak ayat yang menyatakan kejamakan dalam diri Allah.

Lebih jelas lagi di dalam Perjanjian Baru, seperti Matius 3:16-17 mencatat bahwa: "ketika Yesus dibaptis, Bapa berbicara dari Surga dan Roh Kudus turun dalam wujud seperti burung merpati." Peristiwa ini menunjukkan dengan jelas adanya "kejamakan" dalam diri Allah.

Data Alkitab di atas menunjukkan adanya tiga subsistensi atau tiga Pribadi yang berbeda, yaitu Bapa, Putra dan Roh Kudus. Para penulis Yunani memakai istilah hupostatis, dalam bahasa Latin dikenal dengan sebutan persona. Pribadi Bapa, bukan Anak, Pribadi Anak bukan Pribadi Roh Kudus, demikian juga sebaliknya. Pluralitas, atau kejamakan bahkan juga dapat dikatakan keragaman dalam diri Allah diekspresikan melalui tiga Pribadi. Jadi, Bapa, Anak dan Roh Kudus adalah Pribadi yang berbeda.

Selanjutnya, pluralitas dalam diri Allah ini terlihat melalui pekerjaan masing-masing Pribadi. Artinya setiap pribadi dalam Tritunggal memiliki peran yang berbeda, secara khusus dalam opera ad extra dimana Bapa sebagai Pencipta, pemelihara, Anak sebagai Penyelamat dan Penebus dan Roh Kudus melahirbarukan, menghibur dan memelihara Orang Kristen.

Bapa-bapa gereja awal, Ignatius, Klement dari Aleksandria dan Origen, misalnya mampu untuk mengekspresikan aspek dispensasi ilahi. Dimana konsep ekonomi menjadi cara mengintegrasikan pluralitas, mempertahankan kekayaan dan keragaman cara dari satu Allah dalam dunia. ${ }^{31}$

Allah pada diri-Nya sendiri ad intra (adanya subsistensi-subsistensi: Bapa, Anak dan Roh Kudus) dan di luar diri-Nya melalui karya-Nya opera ad extra (Tiga Pribadi melalui pekerjaan masing-masing) Irenieus memiliki konsepsi yang kaya mengenai konsep Tritunggal ekonomi. Kita dapat mengatakan bahwa Irenaeus mampu memberikan konsep yang sangat koheren dan memuaskan dari konstitusi ilahi dan keterlibatan dalam ruang dan waktu dalam dunia ciptaan-Nya. ${ }^{32}$ Hal ini merupakan keunikan doktrin Tritunggal, secara ekonomi, Allah terlibat aktif dalam sejarah manusia.

Seperti apa yang dikatakan oleh Frame bahwa: "Tritunggal bukan semata-mata satu dan semata-mata tiga, melainkan selalu tiga di dalam satu. Maka ciptaan merupakan kesatuan dalam kejamakan.",33

31 Colin E. Gunton, The One,The Three And The Many: God, Creation And The Culture of Modernity (New York: Cambridge University Press), 158.

32 Colin E. Gunton, The One, The Three And The Many: God, Creation And The Culture of Modernity (New York: Cambridge University Press), 159.

33 John Frame, Suatu Analisa Terhadap Pemikirannya Cornelius Van Til (Surabaya: Momentum, 2002), 139. 


\section{Equalitas "Tiga Persona" Allah}

Bapa, Anak dan Roh Kudus sama-sama Allah yang tunggal dan esensi yang tidak terbagi-bagi dan segala kesempurnaan dan prerogatif ilahi, adalah kepunyaan dari masing-masing Pribadi dalam pengertian dan derajat yang sama. ${ }^{34}$ Bapa, Anak dan Roh Kudus sehakekat, setara, sekedudukan, seesensi, merupakan tiga pribadi yang berbeda, tetapi satu Allah. Satu keberadaan, tiga Pribadi, atau tiga Pribadi dalam satu keberadaan. Bapa tidaklah lebih mulia dan lebih tinggi derajat-Nya daripada Anak, demikian juga Anak tidaklah lebih tinggi derajatnya daripada Roh Kudus, demikian juga sebaliknya.

Artinya, masing-masing Pribadi adalah Allah sepenuhnya, memiliki semua atribut ilahi. Pribadi-pribadi itu bukankah bagian-bagian dari Allah, seolah-olah Satu Pribadi bisa bertindak tanpa kedua Pribadi lainnya. Keberadaan Allah menunjukkan suatu identitas numeral yang mutlak. Ia adalah satu "Keberadaan", bukan tiga; ketiga-tiganya mengambil bagian dari satu "esensi." 35 Satu esensi dalam tiga Pribadi yang sama-sama equal.

Alkitab memberikan data tentang kesetaraan atau derajat yang sama diantara Tiga Pribadi (Bapa, Anak dan Roh Kudus). Dalam Perjanjian Baru Injil Yohanes 5:31 menunjukkan Yesus sebagai saksi, dan Yohanes 5:32, 37a menunjukkan Bapa sebagai "saksi yang lain". Frase "yang lain" menjadi frase kunci. Dalam bahasa Yunani dipakai kata ő $\lambda \lambda$ o (allos). Ada dua kata bahasa Yunani yang berarti "yang lain" allos dan heteros. Allos menunjuk pada "yang lain" dari jenis yang sama, sedangkan heteros menunjuk pada "yang lain" dari jenis yang berbeda. ${ }^{36}$ Sama halnya dengan relasi antara Yesus dengan Roh Kudus. Yesus disebut $\pi \alpha \rho \alpha ́ \kappa \lambda \eta \tau o \varsigma$ (parakletos)dalam I Yohanes 2:1 dan Roh

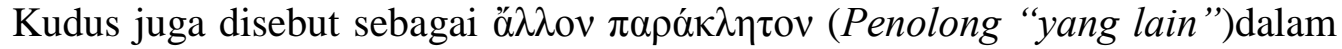
Yohanes 14:16. Dipakai juga kata allos/allon, yang menunjukkan kesederajatan atau kesetaraan kualitas keduanya.

Untuk menjelaskan ketiga Pribadi (Bapa, Anak dan Roh Kudus) equal dalam Kredo Konstantinopel dikatakan sebagai berikut: "Kami percaya bahwa ada satu hakekat (ousia) dari Bapa dan Anak dan Roh Kudus dalam tiga kepribadian yang sempurna (hypostatis) atau tiga Pribadi yang sempurna (prosopois). ${ }^{37}$ Penekanan pada kredo ini sebenarnya terletak pada kesatuan dan kesamaan hakekat (homoousios) yang dimiliki oleh ketiga Pribadi dalam Tritunggal.

Karena itu, Bapa, Anak dan Roh Kudus adalah setara dalam hakekat. Diantara ketiganya tidak ada hakekat yang lebih tinggi atau lebih rendah.

34 Cornelius van Til., Pengantar Theologi Sistematika, 403.

35 John Frame, Suatu Analisis Terhadap Pemikirannya Cornelius Van Til (Suarabaya: Momentum, 2002), 70.

36 W. E. Vine, Vine's Expository Dictionary of Old and New Testament Word (Chichago: Thomas Nelson Publisher, 1985),52.

37 Robert Letham, The Holy Trinity: In Scripture, History, Theology, and Worship (Phillipsburg: P\&R Publishing, 2004), 174. 
Bahkan ketiganya bukan hanya memiliki hakekat yang setara, tetapi juga hakekat yang satu (bukan triteisme ataupun politeisme).

\section{Relasionitas"Tiga Persona" Allah}

Doktrin Allah Kristen, yang bersifat Trinitarian akan memudahkan kita memahami relasi kebersamaan kemajemukan pada diri Allah sendiri dalam kekekalan, sebelum dunia diciptakan. Artinya sebelum dunia diciptakan melalui doktrin Tritunggal Allah memiliki aktivitas relasional di dalam diriNya sendiri. Roger Nicole mengatakan bahwa:

Yet the doctrine of the trinity to apprehend in God something of his own inner life and to see in him the intimate attachment of the Father to the Son, of the son to the father, of both them to the holy spirit, and the holy spirit to both of them. ${ }^{38}$

Schaffer mengatakan bahwa: tiga Pribadi saling mengasihi dan saling berkomunikasi, sebelum adanya semua hal yang lain (sebelum penciptaan) ${ }^{39}$ Apsek trinitarianisme dikenal dengan istilah perichoresis atau dalam bahasa Latin circumincessio adalah doktrin yang menunjukkan saling berdiamnya tiga Pribadi dari Tritunggal. Dimana satu sama lain, berada dalam kesatuan. Istilah ini didefinisikan sebagai pemahaman dan berdiamnnya tiga Pribadi secara timbal balik dalam satu dan lainnya. Dalam konsepsi Yunani tentang Tritunggal ada penekanan pada pemahaman timbal balik dari tiga Pribadi, dalam keastuan esensi Ilahi. Dalam gagasan Latin, penekanannya pada relasi internal dari tiga Pribadi. ${ }^{40}$

Didalam pembahasan teologi Trinitarian maka isu tunggal yang dapat dikemukakan berdasarkan kesepakatan bersama menunjukkan sikap antusiasme kolektif yang disebut dalam kategori "relasionitas."

\section{IMPLIKASI PRAKTIS-RELASIONAL BAGI HIDUP ORANG KRISTEN}

38 Peter Toon \& James D Spiceland. ed., One God In Trinity (London: Samuel Bagster \& Sons Ltd, 1980), 7.

39 Francis A. Schaeffer, Ia Ada di Sana dan Ia Tidak Diam (Surabaya: Momentum, 2012), 37.

40 Alan Richardson \& John Bowden, The Westminster Dictionary of Christian Theology (Philadelphia: The Westminster Press, 1983), 112; bdk, Van Til, 409 mengatakan bahwa Kesatuan yang intim ini diungkapkan di dalam Gereja Yunanidengan kata perichooresis, yang dalam bahasa Latin dijelaskan dengan kata-kata inexistentia, inhabitatio, dan intrcommunio (koeksistensi,kohabitasi dan interkomuni).

41 David S. Cunningham, These Three Are One: the Practice of Trinitarian Theology (Massachusetts: Blackwell Publisher, 1998), 25. 
Semua konsep memiliki konsekuensi arti maupun maknanya. Demikian juga sebuah doktrin itu memiliki implikasi logis berkenaan dengan kehidupan praktis setiap orang yang meyakininya, sehingga konsep ataupun doktrin yang dianut terimplementasikan dalam kehidupan sehari-hari.

Doktrin Trinitas sama seperti formulasi doktrinal lain dari iman Kristen, harus dipikirkan dengan serius. Ini adalah doktrin yang menyediakan kita dengan wawasan asli ke dalam realitas ilahi. Hal ini dimaksudkan untuk memberikan makna bagi kehidupan Kristen dan ibadah. ${ }^{42}$ Artinya implikasi dari doktrin Tritunggal bagi iman Kristen sangat kaya, sebab doktrin ini sangat fundamental dalam memahami Allah dan relasinya dengan dunia, khususnya dalam kaitannya dengan penebusan. Sebagaimana semua doktrin Kristen berhulu pada doktrin Tritunggal menjadi fondasi serta tiang keseluruhan doktrin, bahkan akhirnya bermuara juga pada Allah Tritunggal, maka tidak bisa tidak, ini mempengaruhi kehidupan umat Tuhan baik segi ibadah maupun relasi sosialnya. Karena itu, Penulis menemukkan implikasi praktis-relasional doktrin Tritunggal yang harus menjadi pijakan cara tindak atau prilaku orang Kristen hidup ditengah-tengah dunia yang majemuk.

\section{Singularitas dalam Pluralitas: Sikap Hidup Yang Inklusif dan Toleran}

Dalam Allah ada kejamakan, tetapi kejamakan itu tidak saling menyerang, menjauhkan diri, atau menghancurkan. Yang tiga adalah satu, tanpa jatuh dalam bahaya menjadi sama atau seragam (tresunum sunt, non unus) Allah bukanlah kesatuan yang seragam dan sama, melainkan kesatuan dari yang tidak seragam dan tidak sama. ${ }^{43}$

Semangat kebersamaan, hidup dalam kasatuan ditengah pluralitas adalah refleksi doktrin Tritunggal. Kejamakan tidak harus bertendensi pada perpecahan atau segmentasi-segmentasi golongan kepercayaan dan etnis yang heterogen. Sebaliknya, ditengah hidup manusia yang plural tercipta kesatuan antara satu dengan yang lainnya. Tanpa harus memaksa yang "berbeda" menjadi sama dengan golongan tertentu. Pluralitas bukanlah ancaman. Justru adaanya kesatuan dalam kemajemukan merupakan prinsip hidup yang niscaya dalam hidup manusia, karena di dalam diri Allah yang Esa terdapat pluralitas dalam singularitas. Schaeffer mengatakan bahwa: "kesatuan dan keragaman tidak mungkin eksis sebelum Allah atau ada dibalik Allah, karena apapun yang paling dulu ada adalah Allah. Doktrin Trinitas merupakan kesatuan dan keragaman adalah Allah sendiri, Tiga Pribadi, satu Allah.”44

Ini merupakan dasar bagi relasi sosial yang transcendental, dimana keberadaan umat Tuhan sebagai gereja bisa berelasi dengan harmonis ke dalam bagian sebuah kelompok sosial. Bukan hidup dalam individilistis, tetapi hidup

42 Lih, Peter Toon \& James D. Spiceland. ed., One God In Trinity (London: Samuel Bagster \& Sons Ltd, 1980), 148-149.

43 Ebenhaizer I. Nuban Timo, Aku Memahami Yang Aku Imani., 32.

44 Francis Scheaffer, Ia Ada Di Sana., 37-38. 
secara kolektif, hidup dalam komunitas, kesatuan antara pribadi-pribadi dalam sebuah relasi yang harmonis. ${ }^{45}$

Trinitas merupakan landasan konseptual yang sangat tepat bagi keharmonisan hidup masyarakat yang berbeda. Itu berarti orang Kristen tidak hidup terpisah atau memisahkan diri dari dunia, tetapi hidup secara bersama dan juga menjadi bagian aktif dari dunia. Hidup bersama dengan orang-orang yang berbeda suku, agama, ras dan antar golongan dalam satu kesatuan atau sebagai bagian yang tak terpisahkan. Pada titik ini, maka hidup yang eksklusif tidaklah menjadi pola atau gaya hidup Kristen. Sebaliknya menampilkan pola hidup yang inklusif, terbuka dan menjadi bagian dari kelompok yang berbeda, menjadi karakteristik hidup Kristiani.

Demikian juga soal toleransi, dimana toleransi antar umat beragama bisa terjadi karena menghargai keberagaman, tanpa harus memaksa menjadi seragam. Prinsip hidup dalam suatu kesatuan di tengah keberagaman, sangat diperlukan sikap yang terbuka pada tataran etis. Sama halnya dengan sikap toleransi, menghargai keberadaan orang yang berbeda dengan kita harus menjadi norma prilaku praktis relasional umat Tuhan.

\section{Equalitas Dalam Relasionitas: Aktualisasi Kasih Yang Setara}

Ajaran Kristen tentang Allah merupakan model dari kualitas persekutuan bagi keharmonisan dalam kehidupan berbangsa dan bernegara di Bumi Bhineka Tunggal Ika. Menurut Timo bahwa:

"Allah adalah satu entitas yang jamak. Pada-Nya ada kehidupan yang berbhineka tunggal ika. Ia adalah sebagai pribadi yang berkomunikasi dan berelasi antara Bapa, Anak, Dan Roh Kudus. Relasi dan komunikasi antara ketiga cara berada itu tidak mengenal hierarki atau subordinasi. Yang satu tidak lebih penting atau utama dari yang lain."

Dalam opera ad extra diantara ketiga subsistensi Tritunggal bersifat submisif. Artinya ketaatan Anak kepada Bapa dalam kesederajatan sesuai dengan rencana Mereka, demikian juga dengan Roh Kudus. Sebaliknya tidak bersifat subordinasi, yang satu superior dan yang lainnya inferior. Dalam pengertian ini, sangat relevan bagi relasi sosial yang mejemuk yang biasanya bertendensi pada sikap dan tindakan antara yang superior terhadap yang inferior.

Prinsip utamanya adalah adanya equalitas dalam relasionitas. Sebuah relasi yang sederajat, sehakekat, setara, sekedudukan didalam kejamakan. Prinsip ini, secara otomatis menolak ekses negatif dari fenomena sosial yang acapkali terjadi dalam kehidupan manusia yang mejemuk. Seperti, fenomena

45 Lihat uraian yang lengkap dalam bukunya, Colin E. Gunton, The One, The Three and The Many: God, Creation And The Culture Of Modernity (New York: Cambridge University Press, 1993), 222-225.

46 Ebenhaizer I. Nuban Timo, Aku Memahami..., 31. 
kaum mayoritas terhadap kaum minoritas, yang merasa lebih utama ataupun lebih tinggi hak dan kedudukannya, sehingga menyebabkan adanya fenomena sikap superioritas golongan tertentu terhadap golongan lain yang inferior; fenomena pertentangan, perselisihan bahkan kekerasan dalam kehidupan berbangsa dan bernegara karena perbedaan etnis dan religi. Kesemuanya ini, bermuara pada sikap individulisme, yang menyebabkan hancurnnya kolektivitas dalam pluralitas.

Sebaliknya, equalitas dalam relasionitas merupakan dasar hidup bersama-sama (kolektivitas) dalam berbagai perbedaan. Arogansi, sikap sewenang-wenang terhadap orang lain, bahkan menganggap orang lain atau golongan tertentu rendah dan tidak berarti, tidak lagi menjadi fenomena yang umum dan wajar dalam kehidupan sosial khususnya di Indonesia.Dengan demikian, terjadi keseimbangan antara individulitas dan kolektivitas. Kepentingan individu tidaklah mengorbankan kepentingan kolektif, demikian juga sebaliknya, kepentingan kolektif tidak mengorbankan individu tertentu. Dan di dalam kolektivitas terdapat equlitas antara individu-individu yang majemuk. Seperti apa yang dikatakanoleh Timo bahwa:"tiap individu berdiam dalam yang lain dan di diami juga oleh yang lain. Mereka bersekutu, bukan saling bersaing merebutkan posisi sebagai yang terutama, atau bahkan saling menghancurkan. ${ }^{47}$ Inilah kekayaan, sekaligus keunikan doktrin Tritunggal sebagai basic beliefsiman Kristen yang dapat diimplementasikan dalam kehidupan manusia, sehingga relasi sosial tercipta dengan harmonismelalui hubungan kasih yang setara.

Relasi yang sederajat dalam Allah Tritunggal ini didasari oleh Kasih sebagai atribut-Nya sendiri. Grenz melihat implikasi teologis doktrin Tritunggal berkenaan dengan esensi Allah yang adalah kasih, sebagai atribut moral-Nya. ${ }^{48}$ Relasi antara tiga Pribadi yang sederajat, setara, sehakekat, sama dalam kasih.

Inilah yang menjadi prinsip hidup praxis bagi orang Kristen.dimana Orang Kristen harus senantiasa mengaktualisasikan kasih yang sederajat kepada siapapun, tanpa memandang bulu. Orang Kristen tidak boleh memandang yang seorang lebih tinggi dari yang lainnya berdasarkan strata sosial. Tidak berlaku hukum "tebang pilih", hukum "pilih kasih," sebab pilih kasih bukanlah kasih itu sendiri. Kasih itu sama rata diperlakukan kepada siapapun. Kualitas kasih sama kepada orang yang berbeda suku, agama, ras dan golongan yang berbeda. Kualitas kasih juga sama kepada yang kaya atau pun yang miskin, kepada yang berpendidikan atau pun tidak, kepada orang yang dipandang masyarakat terhormat atau pun kepada orang yang sianggap sepele, kepada orang yang berada maupun yang tak punya.

47 Ebenhaizer I. Nuban Timo, Aku Memahami..., 34.

48 Stanly J. Grenz, Theology for The Community of God (Grand Rapids: Wm. Eerdmans, 1994), 62. 


\section{Relasi Kerjasama Yang Harmonis}

Bukan hanya relasi dalam kesetaraan atau kesederajatan tetapi juga relasi dalam kerjasama yang harmonis. Persis seperti apa yang dikatakan oleh Timo bahwa: Tritunggal merupakan persekutuan ketiga mode of being Allah ditandai oleh relasi kerja sama yang saling menopang dan melengkapi sehingga pekerjaan-pekerjaan Allah bukan hanya mencapai tujuan, melainkan juga pelaksanaan yang indah (Kej 1:31)."49 Ini merupakan relasi kerjasama yang harmonis dalam opera ad extra. Ketiga Pribadi Allah dalam relasi keilahian setara, sederajat, sehakekat, sama, namun memiliki peran spesifik yang berbeda di dalam rencana penyelamatan orang pilihan sejak semula sampai dunia yang akan datang. Meskipun bisa dibedakan secara spesifik tetapi tidak dalam pengertian yang ekstrim. Karena sesungguhnya antara pekerjaan Pribadi satu dengan yang lainnya tidak bisa terlepas satu dengan yang lainnya, karena peran inipun sifatnya tumpang tindih. Dapat dibedakan Oknumnya dalam tugas personal bagi keselamatan umat-Nya. Bapa yang mengutus Anak (I Yoh. 4:10) Anak turun dari Sorga melakukan kehendak Bapa (Yoh. 6:38) dan Roh Kudus menjamin keselamatan. ${ }^{50}$ Lebih terang lagi jika dilihat dalam kerangka teologi reformed dengan prinsip infralapsarianisme dekrit Allah dalam kekekalan untuk memahami peran Oknum Tritunggal yaitu: Penciptaan - kejatuhan - pemilihan - penebusan. $^{51}$

Gambaran kerjasama yang harmonis dalam tiga Oknum Tritunggal tepat seperti apa yang dikatakan oleh Timo bahwa "Ketiganya selalu ada dan aktif bersama-sama tanpa dapat dipisahkan atau dipertentangkan." 52 Inilah yang saya namakan sebagai prinsip kerjasama yang harmonis. Tiga Oknum berbeda, ketiganya memiliki peran masing-masing, tetapi tidak bertentangan atau berkonflik, tetapi tumpang tindih, karena kesatuannya, Ketiga Oknum adalah satu esensi, tidak ada yang lebih menonjol atau teraibaikan, tetapi terikat dalam sebuhan hubungan kerjasama yang harmonis.

Karena itu, seharusnya Gereja merupakan komunitas yang mudah bekerja sama, berperan aktif dalam dunia, tidak suka pertentangan apalagi konflik. Orang Kristen tidak menutup diri, atau bersikap apatis terhadap dunia luar, tidak berkontribusi apa-apa. Implikasi relasional yang terakhir yang saya bahas doktrin Tritunggal adalah kerjasama yang harmoni.

49 Ebenheazer Nuban I. Timo, Aku Memahami Yang Aku Imani., 34.

50 Lih. Togardo Siburian, “Gagasan Trinitas Keselamatan”., 140.

51 Lih. Togardo Siburian, "Gagasan Trinitas Keselamatan”., 140

52 Ebenhaizer Nuban I. Timo, Aku Memahami Yang Aku Imani., 31 


\section{PENUTUP}

Doktrin Tritunggalyang selama ini diaksiomakan sebagai doktrin yang rumit pada tataran diskursus teologi sistematik, dan cenderung pembahasannya pada ranah apologetik,sesungguhnyajuga memiliki implikasi yang sangat dalam bagi kehidupan praktiis-relasionalorang Kristen. Implikasi tersebut terlihat dalam relasi harmonis Allah Tritunggalbaik pada diri-Nya sendiri (ad intra) maupun di luar diri-Nya (ad extra).

Relasi harmonis Allah Tritunggal nampak dalam keberagaman Tiga Oknum yang berbeda, tetapi dalam satu kesatuan. Relasi di antara ketiga Oknum, yang setara, sederajat, sehakaket, sekedudukan, sebab satu esensi, yaitu satu Allah. Ini menunjukkan nilai praktis-relasional bahwa keperbedaan dalam kesatuan itu mungkin dan bahkan niscaya. Dengan hidup dalam kesatuanmeskipun berbeda maka keharmonisan hidup sosial itu tercipta. Dari prinsip etis ini melahirkan sikap yang inklusif dan toleran. Sikap yang terbuka dan dapat menerima mereka yang berbeda dengan kita. bukan gaya hidup yang tertutup, membenci atau meniadakan yang berbeda, atau bersikap separatif, menganggap orang lain sebagai ancaman yang harus dibinasakan. Inilah yang harus menjadi gaya hidup orang Kristen, berada di tengah dunia, bukan memisahkan diri dari dunia, tetapi hidup terbuka dan menghargai sesama yang lain, apapun bentuk perbadaan yang dijumpai.

Relasi ketiga Oknum Allah Tritunggal, yang penuh kasih yang sederajat, antara Bapa, Anak dan Roh Kudus. Berdiam bersama, bukan dalam relasi hirararki Bapa lebih tinggi dari Anak dan Anak lebih tinggi dari Roh Kudus, tetap berdiam bersama ketiga Oknum dalam mengaktualisasikan kasih yang setara. Ketiga-Nya sama derajat, sama hakekat berdiam bersama, berelasi dalam kasih yang sama. Hal ini menjadi prinsip praktis-relasional agar kita memperlakukan sesama dengan cara yang sama, dengan kualitas kasih yang sama, tanpa membedakan antara satu dengan yang lainnya.

Relasi kerja sama dalam peran dan tugas yang harmonis dari ketiga Oknum Tritunggal juga menjadi prinsip praktis-relasional bagi kita, agar berperan aktif, bekerja sama dengan orang lain, sehingga kita berkontribusi aktif bukan hanya bagi kelompok sendiri,untuk kemajuan bersama, kemajuan pada skop yang lebih luas, negara dan bangsa, bukan hanya dalam gereja.

Akhirnya, isolasi diri, sikap yang individualistik yang hanya mementingkan kelompok sendiri, baik dalam relasi pengungkapan kasih maupun dalam keterlibatan kerja bukanlah menjadi ciri khas praktek hidup orang Kristen. Allah Tritunggal adalah Allah yang berdiam bersama, berelasi dengan harmonis pada dir-Nya sendiri dan juga bekerja bersama dalam tujuan yang sama, keselamatan bagi umat-Nya. 


\section{DAFTAR PUSTAKA}

Ammerman,Nancy T.

2003 "The Dynamics of Christian Fundamentalism: AnIntroduction,"dalam Accounting for Fundamentalism, Marty \& Appleby, eds.Chichago: University of Chichago Press.

Amstrong,Karen.

2013 Berperang Demi Tuhan. Jakarta: Mizan,2013.

Bavink, Herman.

2012 Dogmatika Reformed 2: Allah dan Penciptaan. Surabaya: Momentum

Berkhof, Luis.

2011 TeologiSistematika 1 Doktrin Allah. Surabaya: Momentum.

Boelaars, Huub J. W. M.

2005 Indonesianisasi. Yogyakarta: Kanisius, 2005

Boice, James Montgomery.

2011 Dasar-DasarIman Kristen. Surabaya: Momentum.

Botterweck, G. Johanes dan Helmer Ringgren.

1974 Ed. Theological Dictionary of The Old Testament Vol. I. Grand Rapids: William B Eerdmans Publishing Company.

Cunningham, David S.

1998 These Three Are One: the Practice of Trinitarian Theology. Massachusetts: Blackwell Publisher.

Darmaputera, Eka,

2004 Ed.KonteksBerteologi Di Indonesia: Buku Penghormatan Untuk HUT ke-70 Prof. Dr. P. D. Latuihamallo. Jakarta: BPK Gunung Mulia.

Erickson, Milard J.

2003 Christian Theology Second Edition. Grand Rapids: Baker Books.

Frame, John M.

2002 Suatu Analisa Terhadap Pemikirannya Cornelius Van Til. Surabaya: Momentum. 
Grenz, Stanly J.

1994 Theology for The Community of God. Grand Rapids: Wm. Eerdmans.

Grudem, Wayne.

1994 Systematic Theology: An Introduction to Biblical Doctrine. Grand Rapids: Inter-Varsity Press.

Gunton, Colin E.

1993 The One, The Three And The Many: God, Creation And The Culture of Modernity. New York: Cambridge University Press.

2015 Jurnal Stulos. Vol. 14 No 2, Bandung: STTB, 2015.

Karkkainen,Veli-Matti.

2013 Tritunggal \& Pluralisme Agama. Jakarta: BPK Gunung Mulia.

Leith, John H.

1977 Introduction to the Reformed Tradition. Atlanta: John Knox Press.

Letham, Robert.

2004 The Holy Trinity: In Scripture, History, Theology, and Worship. Phillipsburg: P\&R Publishing.

Matalu, Muriwali Yanto.

2017 Dogmatika Kristen Dari Perspektif Reformed. Malang: GKKR, 2017.

Milne, Bruce.

1982 Know Truth: Handbook of Christian Belief. Downers Grove: InterVarsity Press

Nash, Ronald $\mathrm{H}$.

2008 Konflik Wawasan Dunia. Surabaya: Momentum

Oliphint, K. Scott.

2006 Reason For Faith: Philosophy In The Service Of Theology. Phillipsburg: P\&R Publishing.

Packer, J. I. \& Thomas C. Oden.

2011 Satu Iman: Konsensus Injili. Jakarta: BPK Gunung Mulia. 
Richardson, Alan, \& John Bowden.

1983 The Westminster Dictionary of Christian Theology. Philadelphia: The Westminster Press.

Sairin, Weinata.Gereja,

2006 Agama-Agama Dan Pembangunan Nasional: Bunga Rampai, Jakrta: Guung Mulia.

Schaeffer, Francis A.

2012 Ia Ada di Sana dan Ia Tidak Diam. Surabaya: Momentum.

Til, Cornelius Van.

2010 Pengantar Theologi Sistematik: Prolegomena Dan Doktrin Wahyu, Alkitab Dan Allah. Surabaya: Momentum.

Timo, Ebenhaizer I. Nuban.

2012 Aku Memahami Yang Aku Imani. Jakarta: BPK Gunung Mulia.

Toon, Peter\& James D. Spiceland. Ed.

1980 One God In Trinity. London: Samuel Bagster \& Sons Ltd.

Vine, W. E.

1985 Vine's Expository Dictionary of Old and New Testament Word. Chichago: Thomas Nelson Publisher.

Wuthnow, Robert and Mattew P. Lawson.

tt "Sources of Christian Fundamentalism in the United States,". 